\title{
Magnetic and dielectric properties of $\mathrm{Fe}_{3} \mathrm{BO}_{6}$ nanoplates prepared through self-combustion method
}

\author{
Kalpana Kumari \\ Department of Metallurgical and Materials Engineering \\ National Institute of Technology, Karnataka \\ Surathkal, Mangalore-575025, India \\ 0312.kalpana@gmail.com
}

\begin{abstract}
Received 23 November 2017; Revised 10 December 2017; Accepted 11 December 2017; Published 9 January 2018
In the present investigation, a facile synthesis method is explored involving a self-combustion of a solid precursor mixture of iron oxide $\mathrm{Fe}_{2} \mathrm{O}_{3}$ and boric acid $\left(\mathrm{H}_{3} \mathrm{BO}_{3}\right)$ using camphor $\left(\mathrm{C}_{10} \mathrm{H}_{16} \mathrm{O}\right)$ as fuel in ambient air in order to form a single phase $\mathrm{Fe}_{3} \mathrm{BO}_{6}$ crystallites. X-ray diffraction (XRD), Field emission electron microscopy (FESEM), magnetic, and dielectric properties of as prepared sample are studied. From XRD pattern, a single phase compound is observed with an orthorhombic crystal structure (Pnma space group), with average crystallite size of $42 \mathrm{~nm}$. A reasonably uniform size distribution of the plates and self-assemblies is retained in the sample. A magnetic transition is observed in dielectric permittivity (at $\sim 445 \mathrm{~K}$ ) and power loss (at $\sim 435 \mathrm{~K}$ ) when plotted against temperature. A weak peak occurs near $330 \mathrm{~K}$ due to the charge reordering in the sample. For temperatures above the transition temperature, a sharp increase of the dielectric loss is observed which occurs due to the presence of thermally activated charge carriers. A canted antiferromagnetic $\mathrm{Fe}^{3+}$ ordering in a $\mathrm{Fe}_{3} \mathrm{BO}_{6}$ lattice with a localized charge surface layer is an apparent source of exhibiting a ferroelectric feature in this unique example of a centrosymmetric compound. An induced spin current over the $\mathrm{Fe}$ sites thus could give rise to a polarization hysteresis loop. Due to the presence of both ferromagnetic as well as polarization ordering, $\mathrm{Fe}_{3} \mathrm{BO}_{6}$ behaves like a single phase multiferroic ceramics.
\end{abstract}

Keywords: Self-combustion; nanoplates; magnetic properties; dielectric properties; polarization; centrosymmetric.

\section{Introduction}

The iron oxyborates $\mathrm{Fe}^{2+} \mathrm{Fe}^{3+} \mathrm{OBO}_{3}, \mathrm{Fe}_{2}^{2+} \mathrm{Fe}^{3+} \mathrm{O}_{2} \mathrm{BO}_{3}$, or $\mathrm{Fe}_{2}^{3+} \mathrm{Fe}^{3+} \mathrm{O}_{3} \mathrm{BO}_{3}$ divulge multifunctional magnetic, electrical and dielectric properties, which can be tuned usefully with a proper combination of iron valence of $\mathrm{Fe}^{2+}, \mathrm{Fe}^{3+}$, and relative $\mathrm{O}^{2-}$ density. ${ }^{1-8}$ This is required for applications of information storage, spintronics, magnets, and power sources for electric and hybrid vehicles. ${ }^{1,2,4-6}$ Biocompatible borates have bright future in terms of biological and medicinal compounds. ${ }^{9,10}$ Particularly, the compound $\mathrm{Fe}_{3} \mathrm{BO}_{6}$, which consists of only one kind of $\mathrm{Fe}^{3+}\left(3 \mathrm{~d}^{5}\right)$ spins, offers other emerging usages of color pigments, catalysts, barcodes, drugs, and biological tools. ${ }^{9}{ }^{10}$ In bulk $\mathrm{Fe}_{3} \mathrm{BO}_{6}$ crystals, the $3 d^{5}\left(\mathrm{Fe}^{3+}\right)$ spins in a canted antiferromagnet displays an interesting magnetic orientational phase transition from one weak ferromagnet state $\Gamma_{2}$ to another ferromagnetic state $\Gamma_{4} \cdot{ }^{3,11}$ It results in a magnetoacoustic anomaly of a firstorder phase transition near $448 \mathrm{~K}^{11} \mathrm{~A}$ transition $\Gamma_{2} \rightarrow \Gamma_{4}$ occurs at $415 \mathrm{~K}$ in terms of the magnetization and coercivity $\left(H_{c}\right)$ of an intermediate nature of the first and second order transitions. ${ }^{3}$ The low temperature state $\Gamma_{2}$ has the spins aligned in the [001] direction with the spontaneous moment lying in the [100] direction. On heating, the spins turn up along the [100] axis in the state $\Gamma_{4}$ with the spontaneous moment rotated along the [001] axis. At the $\Gamma_{2} \rightarrow \Gamma_{4}$ transition, the weak magnetic moment rotates by $90^{\circ}$ in the (a, c) plane from $c$-axis to $a$-axis. A thermal variation of magnetic anisotropy $\left(H_{a}\right)$, which passes through zero at the transition, evolves the transition. ${ }^{3,12}$ Ultrafast spin-dynamics observed in such systems has renewed interest in this kind of phase transitions. ${ }^{13,14}$

An iron oxyborate with variable cationic valances adapts variable effective valence states, coordination number of cations with the $\mathrm{O}^{2-}$ ions in an oxygen polyhedron, and $\mathrm{O}^{2-}$ fraction with respect to the cations. Ultimately, it modifies single magnetic domains whose response in terms of magnetic properties highly depends on their average size, shape and surface topology. These local microscopic modifications affect functional properties such as structural, magnetic and dielectric properties. The electric, magnetic and structural order parameter can couple one another in a single system yield simultaneous effects on tailored properties ${ }^{15,16}$ useful for the applications. Most of the studies are limited to bulk oxyborates prepared by a conventional solid state reaction. A nanoscale borate is rarely prepared so far except $\mathrm{Fe}_{3} \mathrm{BO}_{5}$ nanorods are made recently using a hydrothermal method, ${ }^{17}$ or a solution phase reaction, ${ }^{8}$ and spherical $\mathrm{Fe}_{3} \mathrm{BO}_{6}$

This is an Open Access article published by World Scientific Publishing Company. It is distributed under the terms of the Creative Commons Attribution 4.0 (CC-BY) License. Further distribution of this work is permitted, provided the original work is properly cited. 
nanoparticles made from a rheological phase reaction. ${ }^{6}$ Quite good numbers of studies are carried in authors' laboratory on the iron borate glasses with varieties of additives that yield small fibrils of ferrites and iron borates with tailored magnetic as well as dielectric properties. ${ }^{18-22}$

In view to this, a new facile synthesis method is developed to obtain a single phase $\mathrm{Fe}_{3} \mathrm{BO}_{6}$ crystallites in the shape of nanoplates. Prepared sample have been characterized in terms of XRD pattern in correlation to the FESEM image to confirm the findings. Apart from this, dielectric properties and polarization characteristics have been studied in correlation to magnetic properties in this paper.

\section{Experimental Procedure}

A facile synthesis method is developed involving a selfcombustion of a solid precursor mixture of $60 \mathrm{Fe}_{2} \mathrm{O}_{3}-40 \mathrm{~B}_{2} \mathrm{O}_{3}$ using camphor as fuel in ambient air to obtain a stable phase $\mathrm{Fe}_{3} \mathrm{BO}_{6}$ crystallites. In this process, a prerequisite blend of $\mathrm{Fe}_{2} \mathrm{O}_{3}$ and $\mathrm{H}_{3} \mathrm{BO}_{3}$ were mixed with camphor $\left(\mathrm{C}_{10} \mathrm{H}_{16} \mathrm{O}\right)$ by grinding in a mortar with a pestle and then mixture was transferred into a petridis and ignited in air for making a typical batch of a total $20 \mathrm{~g}$ sample. All chemicals were analytical grade iron oxide $\left(\mathrm{Fe}_{2} \mathrm{O}_{3}\right)(\geq 99.995 \%)$, boric acid $\left(\mathrm{H}_{3} \mathrm{BO}_{3}\right)(\geq 99.5 \%)$ and camphor $\left(\mathrm{C}_{10} \mathrm{H}_{16} \mathrm{O}\right)(96 \%)$ and were procured from the Merck chemicals (Germany). The fuel-to-oxidant ratio was derived from the total oxidizing and reducing valences of the oxidizer and fuel using the concepts of propellant chemistry. ${ }^{23-25}$ In a theoretical stoichiometric composition, oxidizing valence provided by the oxidizer is equal to reducing valence from the fuel. The chosen fuel with high reducing valences coupled with high enthalpy of combustion $9.27 \mathrm{kcal} / \mathrm{g}$ assisted to reach the ignition temperature and complete the combustion in short duration of the reaction time. ${ }^{26}$ This process initially undergoes melting and later the mixture is decomposed into gaseous products building the ignition temperature well up to $740 \mathrm{~K}$ so as it gives a maximum yield of the product. The total time required to complete the combustion process was less than $60 \mathrm{~s}$. Finally, the product was taken out of petridis and grinding was done to get fine powder of it. As it is analyzed with XRD pattern from the as-prepared powders at selective temperatures, a single phase compound $\mathrm{Fe}_{3} \mathrm{BO}_{6}$ gets formed even while the precursor burns in air. Evidently, this is a very simple, pretty fast and less expensive method, which canbe scaled-up to produce a high quality powder $\mathrm{Fe}_{3} \mathrm{BO}_{6}$ at mass scale.

Crystalline structure and microstructure of the sample were analyzed with XRD and FESEM images under selective conditions. To measure a XRD pattern, a powder sample was loaded in a groove (sample holder) of a perspex plate and then mounted in an X-ray diffractometer of Regaku made model Ultima III. The powder was compressed gently in the groove by using a glass slide to have a specimen of a reasonably smoothened surface over which the X-ray beam is focused. The diffraction data were recorded using a monochromatic radiation of $\mathrm{CuK}_{\alpha}$ of wavelength $\lambda=0.15406 \mathrm{~nm}$ through an iron filter. The data were collected over a wide diffraction angle $2 \theta$ from $20^{\circ}$ to $80^{\circ}$ in most of the samples through a computer, interfaced with the diffractometer, at a scanning speed of $0.02 \%$ or still lower in an applied voltage of $40 \mathrm{kV}$ and $40 \mathrm{~mA}$ current. Field emission scanning electron microscope (FESEM) of Carl ZEISS-SUPRA 40 was used to study SEM images from the crystallized sample (plate) at an accelerated voltage $10-20 \mathrm{kV}$. The dielectric permittivity value and power loss measurements of the $\mathrm{Fe}_{3} \mathrm{BO}_{6}$ nanoplates were carried out by using computer controlled two probes (N4L PSM 1735) LCR impedance analyzer. Compact sample pellet of typically $10 \mathrm{~mm}$ diameter and $3 \mathrm{~mm}$ thicknesses, painted with a silver paste, and was used to measure the data at different frequencies in the range of 0.1 to $10^{4} \mathrm{kHz}$ at $300-525 \mathrm{~K}$ temperatures. To measure the $P-E$ hysteresis loops, the sintered pellet was poled at room temperature in a silicon oil bath (under an electric field $\sim 2 \mathrm{kV} / \mathrm{cm}$ ) for $24 \mathrm{~h}$ by using a DC power supply. Then, the data were recorded from the poled sample by varying applied voltage from 2 to $18 \mathrm{kV}$ (at $100 \mathrm{~Hz}$ ) by using an automatic $P-E$ loop tracer procured from MARINE India. Magnetic properties were studied by using a super conducting quantum interference device SQUID-VSM (Make: EverCool, Quantum Design), which can measure the data at varied temperatures from 4-600 K with an applied field up to $\pm 60 \mathrm{kOe}$. The thermomagnetic curve was obtained over $300-550 \mathrm{~K}$ of temperatures by applying an effectively high magnetic field such as $1 \mathrm{kOe}$.

\section{Results and Discussion}

\subsection{Phase formation and microstructural analyses}

Figure 1 describes the XRD pattern of a phase pure $\mathrm{Fe}_{3} \mathrm{BO}_{6}$ crystallites obtained from an as-burnt $\mathrm{Fe}_{3} \mathrm{BO}_{6}$ powder. The

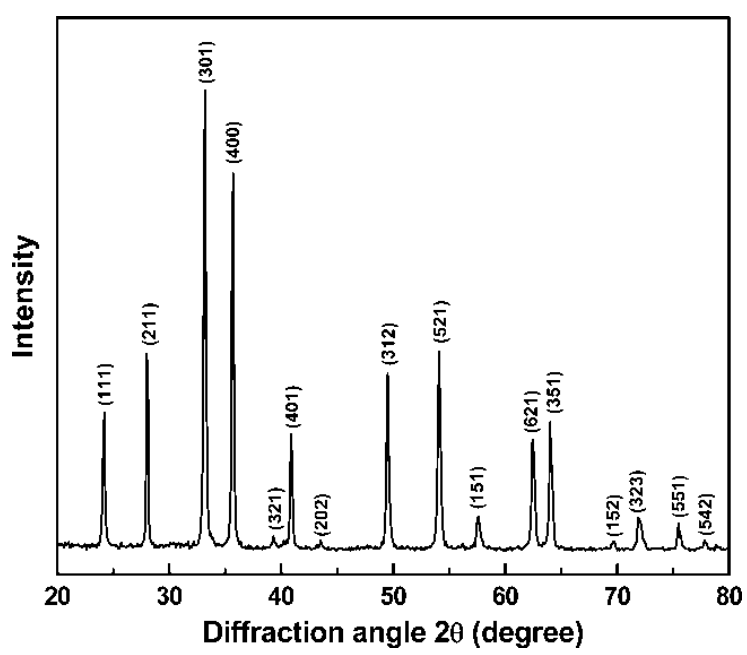

Fig. 1. XRD pattern of $\mathrm{Fe}_{3} \mathrm{BO}_{6}$ crystallites obtained by a selfpropagating combustion of a solid precursor with camphor in ambient air. 
Table 1. The $d_{h k l}$ and $I_{p}$-values in XRD peaks observed in $\mathrm{Fe}_{3} \mathrm{BO}_{6}$ nanocrystallites from a self-propagated combustion of a solid precursor of $60 \mathrm{Fe}_{2} \mathrm{O}_{3}-40 \mathrm{~B}_{2} \mathrm{O}_{3}$ with camphor in open air.

\begin{tabular}{|c|c|c|c|c|c|c|}
\hline \multicolumn{2}{|c|}{ As-prepared (nanocrystallites) } & \multicolumn{2}{|c|}{ Bulk } & \multirow[b]{2}{*}{$h$} & \multirow[b]{2}{*}{$k$} & \multirow[b]{2}{*}{ l } \\
\hline$d_{h k l}(\mathrm{~nm})$ & $I_{P}$ & $d_{h k l}(\mathrm{~nm})$ & $I_{P}$ & & & \\
\hline 0.3675 & 30.7 & 0.3685 & 39.7 & 1 & 1 & 1 \\
\hline 0.3183 & 43.4 & 0.3110 & 4.2 & 2 & 1 & 1 \\
\hline 0.2695 & 100.0 & 0.2681 & 18.1 & 3 & 0 & 1 \\
\hline 0.2513 & 81.9 & 0.2513 & 13.2 & 4 & 0 & 0 \\
\hline 0.2290 & 13.3 & 0.2271 & 16.7 & 3 & 2 & 1 \\
\hline 0.2205 & 25.7 & 0.2190 & 10.7 & 4 & 0 & 1 \\
\hline 0.2078 & 9.4 & 0.2042 & 0.7 & 2 & 0 & 2 \\
\hline 0.1839 & 39.1 & 0.1817 & 0.1 & 3 & 1 & 2 \\
\hline 0.1694 & 43.5 & 0.1685 & 12.0 & 5 & 2 & 1 \\
\hline 0.1598 & 9.4 & 0.1577 & 8.7 & 1 & 5 & 1 \\
\hline 0.1485 & 24.7 & 0.1473 & 0.9 & 6 & 2 & 1 \\
\hline 0.1454 & 28.8 & 0.1442 & 13.9 & 3 & 5 & 1 \\
\hline 0.1349 & 4.3 & 0.1345 & 15.2 & 1 & 5 & 2 \\
\hline 0.1311 & 9.9 & 0.1297 & 1.3 & 3 & 2 & 3 \\
\hline 0.1258 & 9.1 & 0.1250 & 1.3 & 5 & 5 & 1 \\
\hline 0.1226 & 5.7 & 0.1225 & 0.1 & 5 & 4 & 2 \\
\hline
\end{tabular}

interplanar spacings $d_{h k l}$ and peak intensity $I_{P}$-values observed in this sample are compared with the bulk values in Table 1. As shown in Table 1, the most intense (301) peak assumes $d_{h k l}=0.2695 \mathrm{~nm}$ which is very close to the bulk value $0.2681 \mathrm{~nm}$ but differs from it a reasonably enhanced peak intensity. Two reflections (400) and (521) from the lateral surfaces of the lattice in a crystallite share the second and third most intense peaks of the diffractogram at $0.2513 \mathrm{~nm}$ and $0.1694 \mathrm{~nm}$ of $d_{h k l}$-values, respectively. Hence, the formation of a single phase compound with an orthorhombic crystal structure (Pnma space group) is confirmed from the XRD pattern. An average crystallite size $D \sim 42 \mathrm{~nm}$ of $\mathrm{Fe}_{3} \mathrm{BO}_{6}$ crystallites is determined by full width at half maximum (FWHM) values in the XRD peaks using Debye-Scherrer relation. The average lattice parameters $a=1.0290 \mathrm{~nm}, \quad b=0.8125 \mathrm{~nm}$, and $c=0.4535 \mathrm{~nm}$ with density $\psi=4.806 \mathrm{~g} / \mathrm{cm}^{3}$ determined from the $d_{h k l}$ values in the characteristic diffraction peaks shown in Fig. 1 are fairly matching with the reported values $a=1.0050 \mathrm{~nm}, b=$ $0.8550 \mathrm{~nm}$, and $c=0.4470 \mathrm{~nm}\left(\psi=4.744 \mathrm{~g} / \mathrm{cm}^{3}\right)$ on the bulk $\mathrm{Fe}_{3} \mathrm{BO}_{6} \cdot{ }^{27,28}$

The $d_{h k l}$ values describe $a=1.0290 \mathrm{~nm}, b=0.8125 \mathrm{~nm}$, and $c=0.4535 \mathrm{~nm}$ for nanocrystallites, and $a=1.0050 \mathrm{~nm}$, $b=0.8555 \mathrm{~nm}, c=0.4470 \mathrm{~nm}$ for the bulk sample. ${ }^{28}$

Figure 2 depicts FESEM image of $\mathrm{Fe}_{3} \mathrm{BO}_{6}$ crystallites in which mostly round shaped plates (diameter $d=50-140 \mathrm{~nm}$ ) with a few rectangular plates (length $L=50-150 \mathrm{~nm}$ and width $W=20-60 \mathrm{~nm}$ ) are observed. It appears that the $\mathrm{Fe}_{3} \mathrm{BO}_{6}$ image in Fig. 2 is formed by stacking the plate-like basic structures one over other. A reasonably uniform size distribution of the plates and self-assemblies is retained in the sample. Average size and morphology of the structures

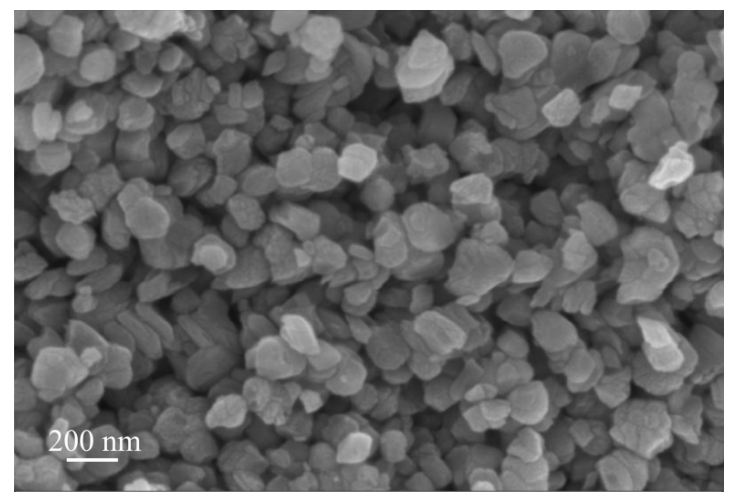

Fig. 2. FESEM image of as prepared $\mathrm{Fe}_{3} \mathrm{BO}_{6}$ crystallites grown in shapes of thin plates and assemblies from a self-propagating combustion of a solid precursor with camphor in open air.

depend strongly on the way of the combustion (preparation technique).

\subsection{Magnetic properties and polarization hysteresis}

Figure 3 shows the $M-H$ curves measured for a sample of $\mathrm{Fe}_{3} \mathrm{BO}_{6}$ nanoplates at different temperatures such as (a) $5 \mathrm{~K}$, (b) $100 \mathrm{~K}$, (c) $200 \mathrm{~K}$, (d) $300 \mathrm{~K}$, (e) $400 \mathrm{~K}$, (f) $450 \mathrm{~K}$, (g) $500 \mathrm{~K}$, and (h) $550 \mathrm{~K}$, (magnified parts in the insets) with magnetic field $50 \mathrm{kOe}$ used here. Magnetic phase- 1 and phase- 2 are shown above the antiferromagnetic phase 0 in the model diagrams. The magnetization does not saturate with the field varied up to $50 \mathrm{kOe}$ at any temperature chosen in this range. It implies that the $\mathrm{Fe}_{3} \mathrm{BO}_{6}$ behaves on average to be a canted antiferromagnet with a large fraction of uncompensated spins (which do not saturate easily at the fields chosen in this experiment) at the nanoplate surfaces. An $S$-shaped magnetization behavior incurs over two major regimes (i) 5$300 \mathrm{~K}$ and (ii) 400-550 K of temperatures, which characterize two canted ferromagnetic states (phases 1 and 2) of the sample against a bulk antiferromagnetic state (phase 0). As it is described in the model diagram in Fig. 3, the phase 1 is a high magnetic phase which bears a magnetization nearly twice compared to the value in the high temperature phase 2 . Parts of the $M-H$ curves magnified in the insets describe part of closed loops of a canted antiferromagnet (or a ferrimagnetic phase), wherein the coercivity $\left(H_{c}\right)$ is raised gradually from $0.167 \mathrm{kOe}$ at $550 \mathrm{~K}$ to as large as $0.361 \mathrm{kOe}$ at $5 \mathrm{~K}$.

A thermomagnetic curve measured over subsequently higher temperatures $300-550 \mathrm{~K}$, as it is plotted in Fig. 4 with an applied $1 \mathrm{kOe}$ field, clearly indicates a distinct $T_{C 1}$ transition near $427 \mathrm{~K}$ before a higher temperature magnetic phase 2 turns-up and extends over higher temperatures. Another $T_{C 2}$ point is marked at $\sim 525 \mathrm{~K}$ in this magnetic phase 2 . As it is well known in shape memory Heusler alloys, ${ }^{29-31}$ a reversible magnetic phase $2 \leftrightarrow$ phase 1 transition shown in heating and cooling cycles in this sample $\mathrm{Fe}_{3} \mathrm{BO}_{6}$ under an applied magnetic field might be useful in developing magnetocaloric effect and its applications. The surface spins in small 


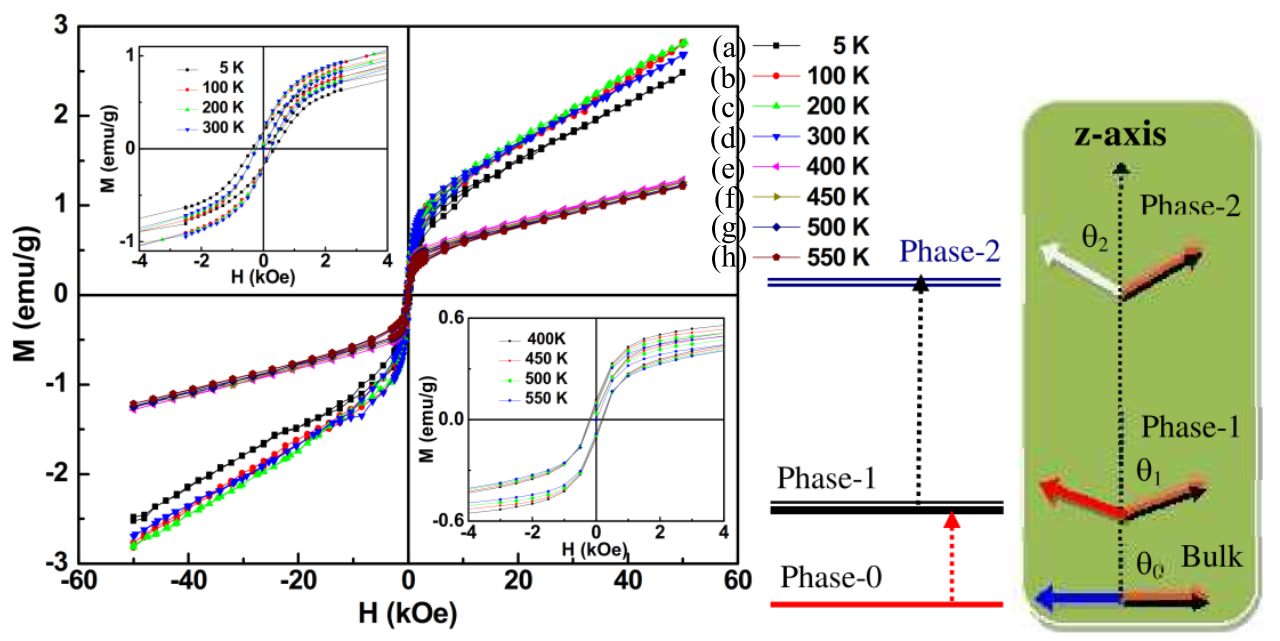

Fig. 3. $M-H$ curves measured for a sample of $\mathrm{Fe}_{3} \mathrm{BO}_{6}$ nanoplates at different temperatures such as (a) $5 \mathrm{~K}$, (b) $100 \mathrm{~K}$, (c) $200 \mathrm{~K}$, (d) $300 \mathrm{~K}$, (e) $400 \mathrm{~K}$, (f) $450 \mathrm{~K}$, (g) $500 \mathrm{~K}$, and (h) $550 \mathrm{~K}$, (magnified parts in the insets) with magnetic field $50 \mathrm{kOe}$. Magnetic phases 1 and 2 are shown above the antiferromagnetic phase 0 in the model diagrams.

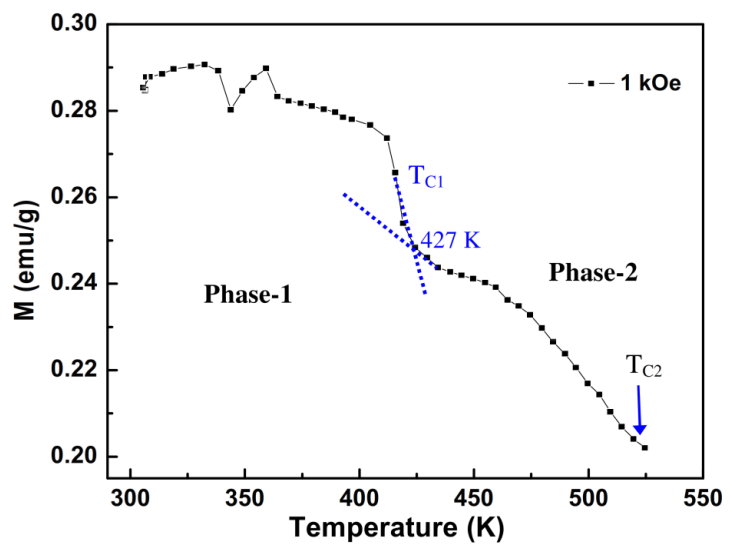

Fig. 4. A thermomagnetic curve measured over $300-550 \mathrm{~K}$ at $1 \mathrm{kOe}$ field for a sample of $\mathrm{Fe}_{3} \mathrm{BO}_{6}$ nanoplates.

crystallites, especially when prepared in a shape of nanoplates, which offer an effectively large surface and in turn a concomitantly large number of the surface spins, play a crucial role in tracing out a reversible phase $2 \leftrightarrow$ phase 1 transition.

Polarization hysteresis loops have been studied for the $\mathrm{Fe}_{3} \mathrm{BO}_{6}$ sample at room temperature and they do not saturate over electric fields $\leq 26 \mathrm{kV} / \mathrm{cm}$ at $100 \mathrm{~Hz}$ frequency as shown in Fig. 5. The ferroelectric features arise in this compound from a canted antiferromagnetic $\mathrm{Fe}^{3+}$ ordering. Interestingly, some other orthoferrites (viz., $\mathrm{SmFeO}_{3}$ $\mathrm{LuFeO}_{3}$ and $\mathrm{YFeO}_{3}$, etc.) occurrences of weak ferroelectric characteristics have been explained to be due to the canted antiferromagnetic ordering of $\mathrm{Fe}^{3+}$ cations. ${ }^{32-35}$ With increasing a bias electric-field, a $P-E$ hysteresis loop thus grows larger and wider as per the magnetoelectric features. In general, three major kinds of the polarization processes involve (i) highly polarizable polarons, (ii) local displacements of the space charges and ionic vacancies, and

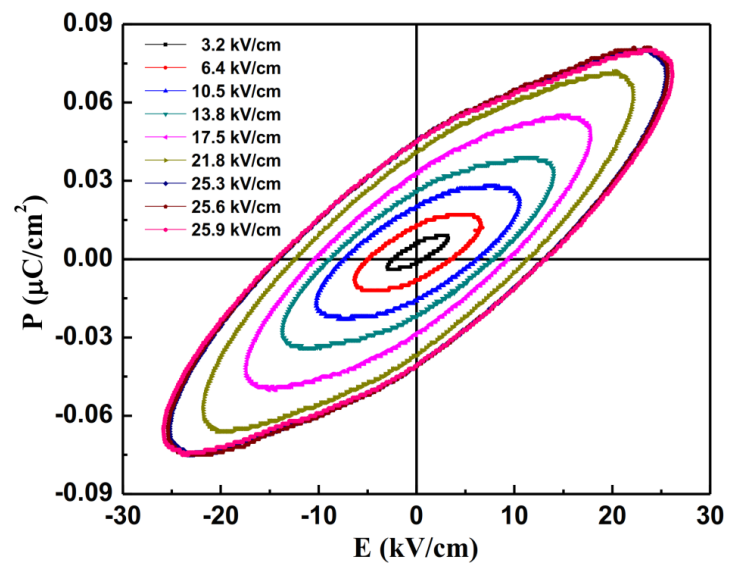

Fig. 5. $P-E$ hysteresis loops for $\mathrm{Fe}_{3} \mathrm{BO}_{6}$ nanoplates at room temperature with various applied fields.

(iii) reorientation of switchable domains. In Fig. 5, an asymmetric shape of the $P-E$ loop is shown which expands progressively over remnant polarization $\left(P_{r}\right)$ and coercivity $\left(E_{c}\right)$ upon an applied field increased from \pm 3.2 to $\pm 25.9 \mathrm{kV} / \mathrm{cm}$. With increasing field, the maximum polarization $\left(P_{s}\right), P_{r}$ and $E_{c}$ values increase progressively in the surface charge species, and uncompensated magnetic spins share the high field polarization. A discontinuous loop as it is seen over here possibly arises due to a field induced reorientation of switchable ferroelectric domains, while an asymmetric shape of it propagates on an electric field induced magnetic effect in the domains. At room temperature, a maximum polarization of $P_{s}=0.08 \mu \mathrm{C} / \mathrm{cm}^{2}$ is observed along with $P_{r}=0.04 \mu \mathrm{C} / \mathrm{cm}^{2}$ and $E_{c}=13.8 \mathrm{kV} / \mathrm{cm}$ at an applied field up to $25.9 \mathrm{kV} / \mathrm{cm}$. This novel result demonstrates the importance of $\mathrm{Fe}_{3} \mathrm{BO}_{6}$ in devising newer ferroelectric material with superior functionalized properties of surface confined ideal single domains. 


\subsection{Dielectric characteristics}

As described elsewhere, ${ }^{36,37}$ the frequency dependent complex dielectric permittivity of a material thus can be written in a simple form as

$$
\varepsilon=\varepsilon^{\prime}-j \varepsilon^{\prime \prime},
$$

where $\varepsilon$ is the resultant value with $\varepsilon^{\prime}$ the real part and $\varepsilon^{\prime \prime}$ the imaginary part of it.

The $Z=Z^{\prime}-j Z^{\prime \prime}$ value is related to the relative permittivity $\varepsilon=\varepsilon^{\prime}-j \varepsilon^{\prime \prime},=\left(j \omega C_{0} Z\right)^{-1}$, where $\omega=2 \pi f$ is the angular frequency and $C_{0}=\varepsilon_{0} S \ell^{-1}$ is the geometrical capacitance with $\varepsilon_{0}=8.854 \times 10^{-12} \mathrm{Fm}^{-1}$ the permittivity of the free space and $S$ the area of the electrode deposited on the sample of thickness $\ell$.

The power-loss can be expressed as

$$
\tan \delta=\frac{\varepsilon^{\prime \prime}}{\varepsilon^{\prime}} .
$$

An antiferromagnetic spins reorientation transition at $415 \mathrm{~K}$ with Néel temperature $T_{N}=508 \mathrm{~K},{ }^{3,11}$ of compound $\mathrm{Fe}_{3} \mathrm{BO}_{6}$ provides a model system for devising multifunctional properties for actuators, transducers, and storage devices. In this argument, $\varepsilon_{r}$-value and power loss have been studied at different temperatures $300-550 \mathrm{~K}$ and frequencies $0.1-$ $10^{3} \mathrm{kHz}$ of $\mathrm{Fe}_{3} \mathrm{BO}_{6}$ nanoplates. Figure 6 plots $\varepsilon_{r}$-values measured as a function of frequency at different temperatures such as (a) $375 \mathrm{~K}$ (b) $400 \mathrm{~K}$, (c) $425 \mathrm{~K}$, and (d) $450 \mathrm{~K}$. The inset presents a modified profile in enhanced $\varepsilon_{r}$-value at room temperature. As it is portrayed in the inset, at room temperature, $\varepsilon_{r}$-value gets enhanced to be as large as $\sim 350$ at low frequency such as $100 \mathrm{~Hz}$ due to the presence of a bonded $\mathrm{B}_{2} \mathrm{O}_{3}$ surface layer on the $\mathrm{Fe}_{3} \mathrm{BO}_{6}$ nanoplates. The $\varepsilon_{r}$-value, which is decreasing regularly on increasing frequency from 0.1 to $10^{3} \mathrm{kHz}$, rises-up progressively in a thermally activated dielectric polarization process of the charge carriers on

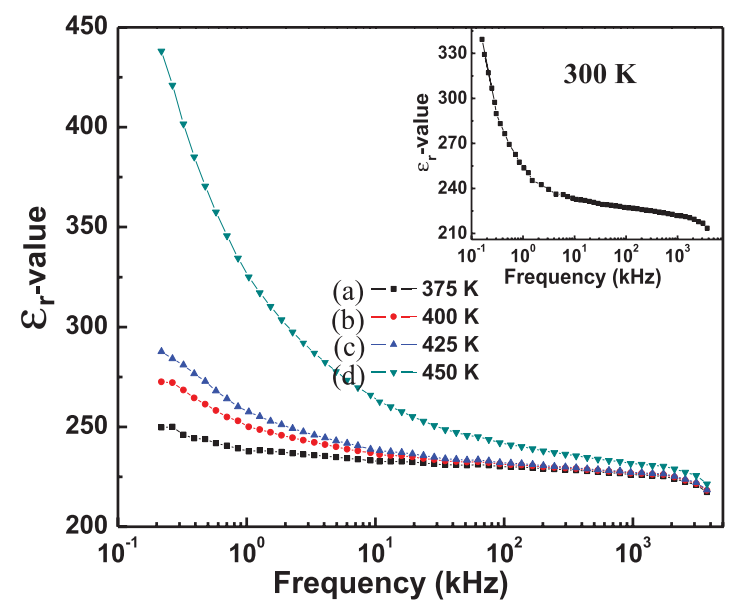

Fig. 6. Frequency dependence variation of $\varepsilon_{r}$-value for $\mathrm{Fe}_{3} \mathrm{BO}_{6}$ nanoplates at different temperatures such as (a) $375 \mathrm{~K}$ (b) $400 \mathrm{~K}$, (c) $425 \mathrm{~K}$, and (d) $450 \mathrm{~K}$. The inset presents a modified profile in enhanced $\varepsilon_{r}$-value at room temperature.

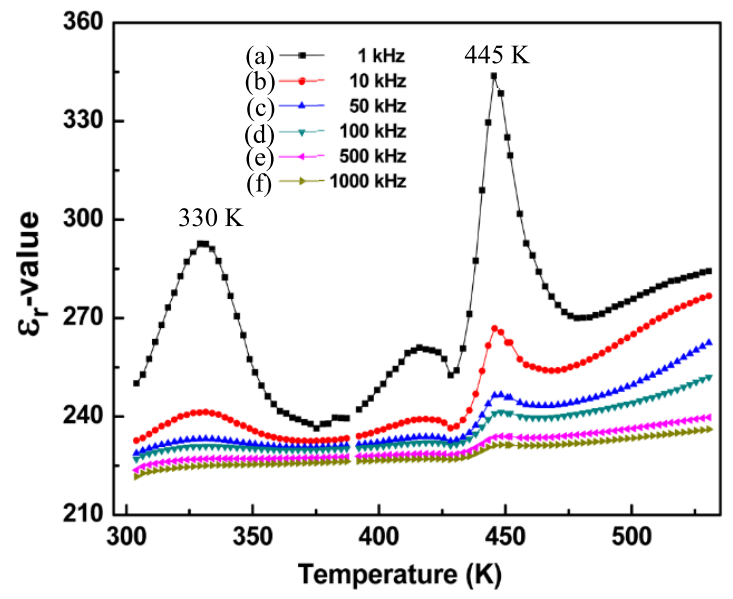

Fig. 7. Temperature dependence variation of $\varepsilon_{r}$-value for $\mathrm{Fe}_{3} \mathrm{BO}_{6}$ nanoplates at different frequencies (a) $1 \mathrm{kHz}$, (b) $10 \mathrm{kHz}$, (c) $50 \mathrm{kHz}$, (d) $100 \mathrm{kHz}$, (e) $500 \mathrm{kHz}$, and (f) $1000 \mathrm{kHz}$.

increasing temperatures. ${ }^{38}$ Two kinds of the charge carriers can be proposed on account of the frequency dependence $\varepsilon_{r}$-value. At low frequencies, the charges accumulate at the interface between the sample and electrodes, i.e., the space charge polarization, describing so high $\varepsilon_{r}$-value which falls down rapidly against the frequencies. When one considers free charge motion of the majority carriers, such species primarily include oxygen ion vacancies and/or interstitials which could pick-up a credibly fast temperature limited thermal diffusion. Figure 7 shows the temperature dependence variation of $\varepsilon_{r}$-value at different frequencies (a) $1 \mathrm{kHz}$, (b) $10 \mathrm{kHz}$, (c) $50 \mathrm{kHz}$, (d) $100 \mathrm{kHz}$, (e) $500 \mathrm{kHz}$, and (f) $1000 \mathrm{kHz}$. In Fig. 7, the $\varepsilon_{r}$-value, which decreases regularly on increasing the frequency, traces a prominent peak at $445 \mathrm{~K}$ (a magnetic transition $\Gamma_{2} \rightarrow \Gamma_{4}$ ) after a weak peak at $330 \mathrm{~K}$ when plotted against temperature. Two kinds of the charge species from the surface and core in $\mathrm{Fe}_{3} \mathrm{BO}_{6}$ can emerge two distinct peaks in a magnetic or ferroelectric transition on thermal induced deviation in their dynamics. The main peak ascribes to the core with a satellite peak shown from the surface species. The weak peak of $330 \mathrm{~K}$ infers to a charge reordering in the surface species.

Figure 8 shows the frequency dependence variation of power-loss at different temperatures such as (a) $300 \mathrm{~K}$, (b) $325 \mathrm{~K}$, (c) $375 \mathrm{~K}$, (d) $425 \mathrm{~K}$, (e) $475 \mathrm{~K}$, and (g) $525 \mathrm{~K}$ for $\mathrm{Fe}_{3} \mathrm{BO}_{6}$ nanoplates. The inset plots a peculiarly enhanced power-loss at onset of the $T_{N}$ point. In Fig. 8, the power-loss decreases with increasing frequency while it increases on increasing the temperature. At low temperatures (at frequencies below $10 \mathrm{kHz}$ ), the power-loss is almost frequency independent. Strong low frequency dispersion up to $10 \mathrm{kHz}$ in the power-loss plot is a consequence of the onset of DC conductivity probably due to the oxygen ion vacancies. Figure 9 shows the temperature dependence variation of power-loss for $\mathrm{Fe}_{3} \mathrm{BO}_{6}$ nanoplates at different frequencies (a) $10 \mathrm{kHz}$, (b) $50 \mathrm{kHz}$, (c) $100 \mathrm{kHz}$, (d) $500 \mathrm{kHz}$, and 


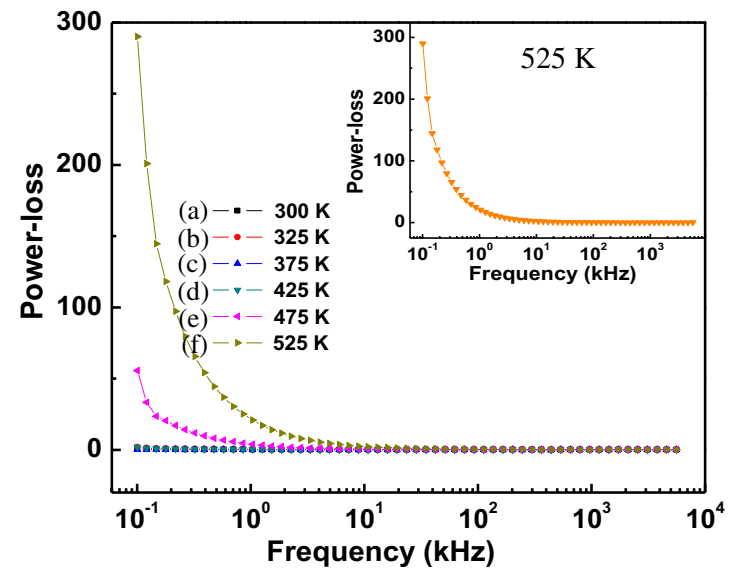

Fig. 8. Frequency dependence variation of power-loss at different temperatures such as (a) $300 \mathrm{~K}$, (b) $325 \mathrm{~K}$, (c) $375 \mathrm{~K}$, (d) $425 \mathrm{~K}$, (e) $475 \mathrm{~K}$, and $(\mathrm{g}) 525 \mathrm{~K}$ for $\mathrm{Fe}_{3} \mathrm{BO}_{6}$ nanoplates. The inset plots a peculiarly enhanced power-loss at onset of the $T_{N}$ point.

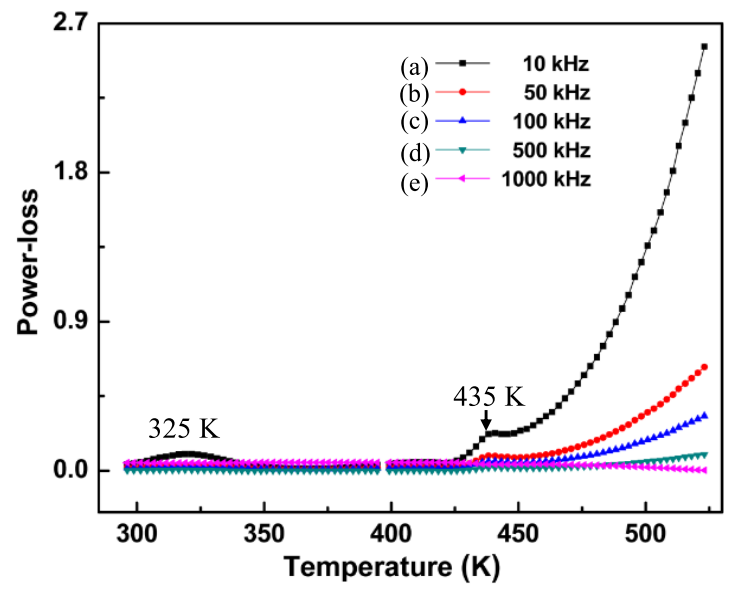

Fig. 9. Temperature dependence variation of power-loss for $\mathrm{Fe}_{3} \mathrm{BO}_{6}$ nanoplates at different frequencies (a) $10 \mathrm{kHz}$, (b) $50 \mathrm{kHz}$, (c) $100 \mathrm{kHz}$, (d) $500 \mathrm{kHz}$, and (e) $1000 \mathrm{kHz}$.

(e) $1000 \mathrm{kHz}$. In Fig. 9, A magnetic transition $\Gamma_{2} \rightarrow \Gamma_{4}$ is obtained at $435 \mathrm{~K}$ with a charge reordering near $325 \mathrm{~K}$. This is possibly due to preponderant $\mathrm{DC}$ conductivity contribution as a consequence of large grain boundaries favoring intergrain conductivity. For temperatures above the transition point, a sharp increase of the dielectric loss is representative of thermally activated charge carriers. It is strongly frequency dependent as it involves interaction of free charge carriers in the grain boundaries with an increased conductivity. ${ }^{39,40}$

\section{Conclusions}

In summary, a new class of a magnetodielectric compound is developed by self-combustion method in a specific shape of $\mathrm{Fe}_{3} \mathrm{BO}_{6}$ nanoplates in correlation to the microstructure. The formation of a single phase $\mathrm{Fe}_{3} \mathrm{BO}_{6}$ compound was confirmed through XRD pattern. Magnetic transition is observed in dielectric characteristic plot which can be correlated with magnetic properties. The ferroelectric features arise from a canted antiferromagnetic $\mathrm{Fe}^{3+}$ ordering in a self-confined $\mathrm{Fe}_{3} \mathrm{BO}_{6}$. Due to the presence of both ferromagnetic as well as polarization ordering, $\mathrm{Fe}_{3} \mathrm{BO}_{6}$ behaves like a single phase multiferroic ceramics. Co-existence of magnetic and dielectric properties in such compounds is highly important for magnetoelectric devices, sensors, and other applications.

\section{Acknowledgments}

This work has been partially supported by Science and Engineering Research Board, DST, New Delhi, Government of India (Grant no.: PDF/2016/003784).

\section{References}

${ }^{1}$ J. P. Attfield, A. M. T. Bell, L. M. R. Martinez, J. M. Greneche, R. Retoux, M. Leblanc, R. J. Cernik, J. F. Clarke and D. A. Perkins, Synthesis, structure and properties of a semivalent iron oxoborate, $\mathrm{Fe}_{2} \mathrm{OBO}_{3}$, J. Mater. Chem. 9, 205 (1999).

${ }^{2}$ J. L. C. Rowsell, J. Gaubicher and L. F. Nazar, A new class of materials for lithium-ion batteries: Iron (III) borates, J. Power Sources 97-98, 254 (2001).

${ }^{3}$ L. T. Tsymbal, Y. B. Bazaliy, L. N. Bezmaternykh, A. S. Waniewska, S. V. Vasiliev, N. Nedelko, A. I. Linnik, A. N. Cherkasov, Y. I. Nepochatykh, V. Y. Dmitrenko, G. N. Kakazei and P. E. Wigen, Orientation phase transition in $\mathrm{Fe}_{3} \mathrm{BO}_{6}$ : Experimental determination of the order of the transition, Phys. Rev. $B$ 74, 134429 (2006).

${ }^{4}$ S. Shimomura, S. Nakamura, N. Ikeda, E. Kaneko, K. Kato and K. Kohn, Structural properties of a mixed valence compound $\mathrm{Fe}_{2} \mathrm{BO}_{4}$, J. Magn. Magn. Mater. 310, 793 (2007).

${ }^{5}$ M. S. Andújar, A. C. Couceiro and M. A. S. Rodríguez, Characterization of the charge ordering state by maximum entropy method, Solid State Commun. 141, 615 (2007).

${ }^{6}$ X. Shi, C. Chang, J. Xiang, Y. Xiao, L. Yuan and J. Sun, Synthesis of nanospherical $\mathrm{Fe}_{3} \mathrm{BO}_{6}$ anode material for lithium-ion battery by the rheological phase reaction method, J. Solid State Chem. 181, 2231 (2008).

${ }^{7}$ D. C. Freitas, M. A. Continentino, R. B. Guimarães, J. C. Fernandes, J. Ellena and L. Ghivelder, Structure and magnetism of homometallic ludwigites: $\mathrm{Co}_{3} \mathrm{O}_{2} \mathrm{BO}_{3}$ versus $\mathrm{Fe}_{3} \mathrm{O}_{2} \mathrm{BO}_{3}$, Phys. Rev. B 77, 184422 (2008).

${ }^{8}$ Y. Liu, S. Peng, Y. Ding, C. Rong, J. Kim, J. P. Liu, Z. L. Wang and S. Sun, Synthesis and characterization of ferroferriborate $\left(\mathrm{Fe}_{3} \mathrm{BO}_{5}\right)$ nanorods, Adv. Func. Mater. 19, 3146 (2009).

${ }^{9}$ L. A. Bauer, N. S. Birenbaum and G. J. Meyer, Biological applications of high aspect ratio nanoparticles, J. Mater. Chem. 14, 517 (2004).

${ }^{10}$ J. Dobson, Remote control of cellular behaviour with magnetic nanoparticles, Nat. Nanotechnol. 3, 139 (2008).

${ }^{11}$ V. Buchelnikov, N. Danshin, D. Dolgushin, A. Isotov, V. Shavrov, L. T. Tsymbal, G. Kakazei, T. Takagi and P. Wigen, The magnetoacoustic anomaly in $\mathrm{Fe}_{3} \mathrm{BO}_{6}, J$. Magn. Magn. Mater. 272-276, 2113 (2004). 
${ }^{12}$ R. Diehl and G. Brandt, Refinement of the crystal structure of $\mathrm{Fe}_{3} \mathrm{BO}_{6}$, Acta Cryst. B 31, 1662 (1975).

${ }^{13}$ A. V. Kimel, A. Kirilyuk, A. Tsvetkov, R. V. Pisarev and T. Rasing, Laser-induced ultrafast spin reorientation in the antiferromagnet $\mathrm{TmFeO}_{3}$, Nature (London) 429, 850 (2004).

${ }^{14}$ N. P. Duong, T. Satoh and M. Fiebig, Ultrafast manipulation of antiferromagnetism of NiO, Phys. Rev. Lett. 93, 117402 (2004).

${ }^{15} \mathrm{G}$. Catalan and J. F. Scott, Physics and applications of bismuth ferrite, Adv. Mater. 21, 2463 (2009).

${ }^{16}$ E. K. H. Salje, Phase Transformations in Ferroelectrics, Ferroelastic And Co-Elastic Crystals (Cambridge University Press, Cambridge, 1990).

${ }^{17} \mathrm{H}$. Qi and Q. Chen, Preparation of plywood-like $\mathrm{Fe}_{3} \mathrm{BO}_{5}$ nanorods by a facile hydrothermal method at low temperature, Chem. Lett. 37, 752 (2008).

${ }^{18} \mathrm{~S}$. Ram, Crystallization of acicular platelet particles of W-type hexagonal strontium ferrite for magnetic recording applications, J. Mater. Sci. 25, 2465 (1990).

${ }^{19} \mathrm{~S}$. Ram, Infrared study of the dynamics of boroxol rings in the crystallization of $\mathrm{BaFe}_{12} \mathrm{O}_{19}$ microcrystals in borate glasses, Phys. Rev. B 51, 6280 (1995).

${ }^{20} \mathrm{~S}$. Ram, Crystallisation of $\mathrm{BaFe}_{12} \mathrm{O}_{19}$ Hexagonal ferrite with an aid of $\mathrm{B}_{2} \mathrm{O}_{3}$ and the effects on microstructure and magnetic properties useful for permanent magnets and magnetic recording devices, J. Magn. Magn. Mater. 82, 129 (1989).

${ }^{21} \mathrm{~S}$. Ram, K. Kumari and R. K. Kotnala, Synthesis of norbergite $\mathrm{Fe}_{3} \mathrm{BO}_{6}$ of single crystallites from a borate glass, Trans. Ind. Ceram. Soc. 69(3), 165 (2010).

${ }^{22}$ K. Kumari, S. Ram and R. K. Kotnala, Frequency-temperature dependent dynamics of dielectrics in ferric oxoborate $\mathrm{Fe}_{3} \mathrm{BO}_{6}$ of cocktail structure of nanorods, Philos. Mag. Lett. 91, 498 (2011).

${ }^{23}$ J. Yang, X. Li, J. Zhou, Y. Tang, Y. Zhang and Y. Li, Factors controlling pure phase magnetic $\mathrm{BiFeO}_{3}$ powders synthesized by solution combustion synthesis, J. Alloys Compd. 509, 9271 (2011).

${ }^{24}$ A. B. Salunkhe, V. M. Khot, M. R. Phadatare and S. H. Pawar, Combustion synthesis of cobalt ferrite nanoparticles-Influence of fuel to oxidizer ratio, J. Alloys Compd. 514, 91 (2012).

${ }^{25}$ R. Köferstein, Synthesis, phase evolution and properties of phasepure nanocrystalline $\mathrm{BiFeO}_{3}$ prepared by a starch-based combustion method, J. Alloys Compd. 590, 324 (2014).

${ }^{26}$ https://www.chemeo.com/cid/28-017-2/Camphor.pdf.

${ }^{27}$ J. G. White, A. Miller and R. E. Nielsen, $\mathrm{Fe}_{3} \mathrm{BO}_{6}$, a borate isostructural with the mineral norbergite, Acta Cryst. B 19, 1060 (1965).
${ }^{28}$ W. F. McClume, JCPDS X-ray Powder Diffraction Files (a) 731385: $\mathrm{Fe}_{3} \mathrm{BO}_{6}$, Joint committee on powder diffraction standards, International centre for diffraction data, Swarthmore, USA (1999).

${ }^{29}$ A. Planes, L. Mañosa and M. Acet, Magnetocaloric effect and its relation to shape-memory properties in ferromagnetic heusler alloys, J. Phys.: Condens. Matter 197, 233201 (2009).

${ }^{30}$ L. Mañosa, D. G. Alonso, A. Planes, E. Bonnot, M. Barrio, J.-L. Tamarit, S. Aksoy and M. Acet, Giant solid-state barocaloric effect in the Ni-Mn-In magnetic shape-memory alloy, Nat. Mater. 9, 478 (2010).

${ }^{31}$ E. S. Taulats, P. O. C. Villa, L. Mañosa, C. Frontera, S. Pramanick, S. Majumdar and A. Planes, magnetocaloric effect in the low hysteresis Ni-Mn-In metamagnetic shape-memory heusler alloy, $J$. Appl. Phys. 115, 173907 (2014).

${ }^{32}$ J.-H. Lee, Y. K. Jeong, J. H. Park, M.-A. Oak, H. M. Jang, J. Y. Son and J. F. Scott, Spin-canting-induced improper ferroelectricity and spontaneous magnetization reversal in $\mathrm{SmFeO}_{3}$, Phys. Rev. Lett. 107, 117201 (2011).

${ }^{33}$ Y. Qin, X. Q. Liu and X. M. Chen, Dielectric, ferroelectric and magnetic Properties of Mn-doped $\mathrm{LuFeO}_{3}$ Ceramics, J. Appl. Phys. 113, 044113 (2013).

${ }^{34}$ M. Shang, C. Zhang, T. Zhang, L. Yuan, L. Ge, H. Yuan and S. Feng, The multiferroic perovskite $\mathrm{YFeO}_{3}$, Appl. Phys. Lett. 102, 062903 (2013).

${ }^{35}$ T. Wang, L. Jin, C. Li, Q. Hu and X. Wei, Relaxor ferroelectric $\mathrm{BaTiO}_{3}-\mathrm{Bi}\left(\mathrm{Mg}_{2 / 3} \mathrm{Nb}_{1 / 3}\right) \mathrm{O}_{3}$ ceramics for energy storage application, J. Am. Ceram. Soc. 98, 559 (2015).

${ }^{36}$ J. R. Macdonald, Impedance Spectroscopy (John Wiley and Sons, New York, 1987).

${ }^{37}$ R. V. Hippel, Dielectric Materials and Applications (Technology Press, New York, 1954).

${ }^{38}$ A. Shukla, N. Shukla and R. N. P. Choudhary, Dielectric characteristics of La-modified $\mathrm{PbTiO}_{3}$ nanoceramics, Phase Transit. 90, 362 (2017).

${ }^{39}$ O. Raymond, R. Font, N. S. Almodovar and J. M. Siqueiros, Frequency temperature response of ferroelectromagnetic $\mathrm{Pb}$ $\left(\mathrm{Fe}_{1 / 2} \mathrm{Nb}_{1 / 2}\right) \mathrm{O}_{3}$ ceramics obtained by different precursors. Part I. structural and thermo-electrical characterization, J. Appl. Phys. 97, 084107 (2005).

${ }^{40}$ T. Wang, J. Hu, H. Yang, L. Jin, X. Wei, C. Li, F. Yan and Y. Lin, Dielectric relaxation and Maxwell-Wagner interface polarization in $\mathrm{Nb}_{2} \mathrm{O}_{5}$ doped $0.65 \mathrm{BiFeO}_{3}-0.35 \mathrm{BaTiO}_{3}$ ceramics, J. Appl. Phys. 121, 084103 (2017). 